\title{
Using Video Recall for Improving Professional Competency in Instructional Consultation
}

\section{David Taylor-Way}

Cornell University

\section{Kathleen T. Brinko}

Appalachian State University

Evidence suggests that the next decade will present educators, and faculty developers in particular, with both a challenge and an opportunity-a challenge to make ends meet fiscally and an opportunity to avoid repeating history. This opportunity owes a great deal to the recent groundswell of concern over the quality of higher education (Bloom, 1987; Hirsch, 1987; Sykes, 1988), a situation that has granted faculty developers a job security similar to that they enjoyed during the early 1970 's.

As the fiscal situation within higher education becomes more strained, however, the field of faculty development will inevitably be scrutinized with an eye to its long-range utility. Amongst our colleagues, we observe a commitment to the profession, a willingness to continue to improve and learn new skills, and a community spirit that leads us to share our knowledge with other developers, both new and veteran. Thus, within our own ranks, we know that we are conducting ourselves professionally. But what about the image we project to the rest of academia? What is our status with tenured faculty and administrators who strive to maintain the traditions of higher education? By what criteria do they evaluate us? Will we continue to pass the test of time and budget deficit? 
We believe that there is one professional activity within faculty development that can withstand the scrutiny of traditional academicians and accountants: instructional consultation. Although instructional consultation has traditionally been used solely to improve faculty clients' teaching, our experience has shown us that some kinds of instructional consultation can also facilitate our own reflection on action (Schon, 1983; 1987) and production of professional knowledge as faculty developers. We found that our own professional growth was particularly stimulated by one kind of instructional consultation: videotape recall (Taylor-Way, $1981 ; 1988)$. Video recall is based on the idea that audible and visible classroom behavior, as captured by videotape, reflects the thoughts and feelings of teachers and students. The goal of this approach as a consulting tool is to help teachers make connections between practice and the underlying experiential factors that govern practice. Similarly, consultation behavior can be captured on videotape; and, like teachers, consultants can use the videotaped sessions to recall their own thoughts and feelings in order to analyze their own behavior.

Many philosophers would challenge the assumption that action is simply a result of thought and feeling. This paper is not the place for such a debate, however. Let us just accept that - given our own experience and the research that has examined teachers' thinking (Bloom, 1953; Clark \& Yinger, 1977; MacKay \& Marland, 1978; Shavelson \& Stern, 1981) - there is some connection between how we think and feel and how we act. For the purposes of this article, it is not necessary to believe that this connection exists, but only to be willing to experiment in order to gain some personal insight into its validity. What we suggest is that practitioners of instructional consultation experiment with using videotape recall both to document and to monitor their own growing knowledge about that practice.

\section{Videotape Consultation and Intervention: A Short History}

Educators and counselors have experimented with videotape since the technology first became available in the early 1960's (Way, 1977). Early users were quite enthusiastic and optimistic about its potential for helping them to understand the intricacies of human interaction (Adams \& Biddle, 1970; Baker, 1970; Bilberstine, 1971; Bloom, 1969; Brantley, 1972; Burke \& Kagan, 1976; Carus, 1968; Dendy, 1971; Eder, 1971; Fuller \& Manning, 1973; Kagan, 1975; Kagan, Krathwohl \& Miller, 1963; Mulac, 
1969; Roush, 1969; Roberts, 1971; Stoller, 1968; Valine, 1974). At that point in history, we social scientists thought technology would save us from ourselves. Government appropriations to higher education were generous, and cost-benefit analysis and demands for accountability were limited.

Unfortunately, those times are long gone. Now many are skeptical of the educational utility of technology. Funding for the social sciences has become extremely limited and competitive. Cost-benefit analysis is commonplace, and accountability is critical.

Like the social and economic milieu, video technology has undergone radical transformation. The quality of images and sound has improved greatly. Charged coupled devices (CCD's) have enabled complete video recording studios to be carried in a small briefcase. Action can be frozen into stable, single-frame images with high-speed shutters. Slide presentations can be recorded in large lecture halls using low-light CCD chip cameras with automatic exposure, focus, power zoom lenses and wireless microphones. Now anyone can produce very acceptable videotape recordings with little or no training or experience.

While both the socioeconomic context and video technology have changed dramatically over the past 25 years, consultation methods using video recordings have not experienced a parallel change. Like our earlier counterparts, many contemporary instructional consultants use videotape to focus on observable presentational techniques, such as gestures, voice intonation and projection, eye contact, use of space, use of audiovisual materials, and the like. Effective use of these techniques can indeed improve instruction, but is neither necessary nor sufficient for effective classroom teaching.

We have already posited that using videotape recordings to examine classroom events can provide a depth of analysis lacking in traditional approaches to instructional consultation with video (Taylor-Way, 1988). Now we propose that videotape recordings can be used by instructional consultants to examine meaningful consultation events - such as interaction patterns, quality of questions, use of periodic summaries, positive reinforcement, and so on. Just as videotape recall can enable consultants to help teachers analyze how they think about teaching, video recall can also provide the medium by which we consultants can analyze how we think about our consultation. 


\section{Using Video Recall to Produce Professional Knowledge in Clients}

In using the videotape recall method with faculty and teaching assistants, instructional consultants have three tasks. First, they help clients to focus on significant, discrete, and adaptable classroom events. Focus is achieved through the use of open-ended leads (Taylor-Way, 1988). Second, they help clients to conceptualize the events that have been focused on. Conceptualizing is the process by which the specific event is abstracted from its original context, identified as a discrete phenomenon, and given a name like "wait time" (Rowe, 1974). Third, they help clients to reframe the way they deal with the concept identified earlier, and then to generate their own principle for handling the situation. This component represents the most complex part of the video recall process, because reframing can take more than one form.

In reframing, clients can be encouraged to develop a principle of teaching to deal with behavior patterns they have conceptualized in the previous step. For example, one faculty member may learn from watching a videotape of herself that she does not allow enough wait time (concept) after asking questions; rather than waiting for her students to answer her questions, she habitually answers her own questions (principle). Dissatisfied with that result, she decides to change her principle: instead of answering her own questions, she will silently count to five. If no student answers after that time, she will rephrase the question (reframed principle).

In reframing, clients can also add a new principle of teaching to an already existing repertoire, since when new patterns emerge, the standard set of strategies often proves insufficient. For example, a teaching assistant may find that if he allows enough wait time after asking questions, students generally respond. At the same time, however, he may be dissatisfied with the quality of discussion; students turn to him for approval after each contribution. With the help of a consultant, the teaching assistant may discover the principle of a second wait-time - that is, after the first student responds to a question. To minimize student dependency, the teaching assistant incorporates an additional wait-time after students' responses to questions when he wants them to react to each others' thoughts; thus, he has a way of facilitating a student-governed discussion (new principle).

Effective use of video recall depends on several important factors. First, consultants must help clients to develop their own concepts and principles to build a framework of professional knowledge about teaching 
(Shulman, 1986). Second, they must establish a safe and trusting atmosphere where instructors feel free to reflect on their own beliefs, expectations, values, and feelings (Blake \& Mouton, 1983; Gallissich, 1982). Third, they must encourage clients to take ownership (Lewis, 1988) of the recall session by allowing them to control the dialogue and summarize important points of the recall session.

How do we know how effective videotape recall is? Two sources of data are available: behavioral and cognitive. Both types of data should be examined - we need to know if changes in practice are evident (behavioral index), and we also need to know how the practitioner's thinking has been influenced (cognitive index). At Cornell University, where we have been using and developing videotape recall since 1978 to assist teachers in learning to teach more effectively, we have collected both forms of data. We monitor behavioral changes by comparing successive videotapes. We receive cognitive development data in the form of written reports submitted by the practitioner after each recall session. In addition to these written reports, verbal evidence of changes in thinking about practice can be found in the second recall session itself. In some cases, we audiotape or videotape recall sessions for subsequent analysis.

Preliminary observations and experience have shown that even after one recall experience, clients become more aware of and sensitive to classroom phenomena. Comparisons of first and second videotapes often reveal changes in behavior that clients describe as conscious and intentional. The written reports reveal how well clients are able to articulate what they have conceptualized from experience, what internal or external cues help govern their growing awareness and sensitivity, and what kind of reframing is occurring in relation to that growing awareness and refocusing. Once our historical data have been analyzed, we will say more about how video recall influences the development of practice.

We have presented a very brief description of videotape recall. The reader is encouraged to consult more comprehensive descriptions of the method (Taylor-Way, 1988) and to contact either of the authors for further information.

\section{Using Video Recall to Produce Professional Knowledge in Consultants}

Schon's (1987) method for educating the reflective practitioner focuses upon the relationship between our ability to articulate our actions and the reasons for them and our ability to control our actions. In the 
above discussion, we examined how consultants can facilitate reflective practice in clients by using videotape to encourage faculty members and teaching assistants to articulate how their thoughts and feelings influence their teaching. Now we would like to turn our discussion to how consultants can facilitate reflective practice in themselves and, thus, continue to professionalize instructional consultation.

Just as videotape recall provides teachers with a means of "giving reason" (Kilbourne, 1988) for their actions in the classroom, it can also give consultants a chance to "reflect on action." Using a videotape of an instructional consultation session as a recall stimulus enables consultants to reconstruct some of the critical cognitive and affective events that influence their own professional practice.

Instructional consultants can improve their practice by using video recall in two ways. First, a consultant can videotape himself or herself using video recall with a client, and can then enlist a colleague consultant to use video recall to help analyze the session. In this case, the consultant needs the cooperation of a colleague who is trained in (or interested in learning) video recall. The colleague uses the same recall methodology outlined previously-focus, conceptualize, and reframe - to assist the consultant in generating principles that will improve his or her effectiveness. The professional growth of both consultants can be fostered if they both obtain videotapes of themselves working with clients and practice doing video recall with each other. In this way, each can hone his or her skills in facilitating clients' focusing, conceptualizing, and reframing, as well as experience what it feels like to be the client. Each consultant also needs the cooperation of a client who is not threatened by having a recall session videotaped. In our experience, most clients are very willing to have their recall sessions videotaped. They already believe that feedback is a vital part of professional development; thus, they usually respect the consultant's desire to obtain feedback for professional development. Besides a verbal explanation of the process and assurance of confidentiality, we provide a written release statement for the client to sign.

The second way that an instructional consultant can use video recall to improve his or her practice is through role-play. In this case, the consultant does not need the cooperation of clients; instead, he or she enlists the cooperation of two colleague consultants who are also interested in learning, or honing their skills in, video recall. In the first session, one of the three participants role-plays the teacher, while the second participant role-plays the consultant using video recall techniques. The third person videotapes the recall session. After the session, the recorder 
conducts a videotape recall session with the consultant. In this way, two of the three colleagues can practice their video recall skills. In the second round, perhaps the next day, the three participants trade roles, and continue to rotate roles until they are comfortable with the process of video recall. We have used this practice at Cornell for the last ten years with great success. To date, we have trained over sixteen consultants to use videotape recall.

The objectives of both methods are threefold: to fine-tune our consulting skills; to expand our consulting repertoire; and to exchange experiences and approaches. Just as we would strongly advise a teacher against viewing and analyzing a videotape of his or her teaching without the assistance of a consultant, so too do we strongly advise a consultant not to view and analyze a videotape of her or his consulting without the assistance of a colleague. The temptation to focus upon superficial behaviors is great and may hinder one's development as a reflective practitioner.

\section{Some Personal Experimentation: David}

The following three episodes are from David Taylor-Way's experimentation with using videotape recall to teach the method to another consultant unfamiliar with it. The episodes are transcribed extracts from a videotape of David and another instructional consultant reviewing a videotape of one of her recall sessions with a teacher.

\section{Episode 1:}

Consultant: I think I have to learn new techniques for dealing with resistance. I've dealt with several faculty members who are eager, who get so excited in the recall session-I mean they're talking faster than I can take notes-or someone who's already very good. They usually seem very receptive to the technique and are happy for any refinements that come out of it. So I see where I need to develop experience is with people who are either afraid to look at this or who are not won over to the fact that they indeed could learn from this.

David: You're saying that's the most challenging part of the work right now.

Consultant: Yeah. The most challenging part is when someone's conception of what a teacher is, is so different from my conception of what they could be. 
David: Uh huh. It sounds to me like part of what you're struggling with here grows out of a lack of a principle to guide you in that situation? Or a lack of range of principles.

Consultant: Maybe an uneasiness with my role, because I really believe that the person owns their own teaching - their own approach, and I have to support them as they investigate that. So there's a part of me that says, "Put your hand over your mouth." You cannot tell this person what teaching can be. Clearly, it's got to come from them. On the other hand, if their idea of what they can or should do is so limited, I have to let them own that feeling that this is what their role is, and how can I broaden it...and I have ideas of how to broaden that - "Let's talk about your best teacher, let's talk about your experience." But in a one-hour recall, when you're looking at a piece of tape, I guess I have not figured out a principle, the guidelines to help that happen.

David: That's something I struggle with all the time, which is how directive do I become. I'm picking up that your style of consulting might be less directive than mine. Frequently, I find myself doing a lot of teaching in a recall session. But I haven't quite put it together yet about my own feeling of the issue of ownership, because, especially when I look at a tape of myself doing a recall where I'm doing a lot of talking, it looks like, and it feels like, I am taking ownership away from the teacher. And I haven't quite worked that out yet. I think that for some people, that's what they want and ask for. But other people, you're not so sure. So when I see myself doing a lot of talking, in retrospect I ask myself whether I should be doing that or not, whether I was being effective or not.

Consultant: Certainly there are cues we go by. You can tell with a person if it even computes. Other times you make one suggestion, and you think, "This is pushing it a little but I'm going to say it anyway," and the person goes "Ah! Right!" The important thing is to reflect on those times and try to figure out what made it work in the one case, but not in the other; or to analyze the most frustrating recalls and try to figure out what went wrong.

In the beginning of this episode, the consultant recognized, and was able to articulate, her problem: that she is ambivalent about how much direction to give to fearful or skeptical teachers. Thus, she was able to focus on and conceptualize the problem with little assistance from David. She had not yet found any "techniques for dealing with resistance," however. David challenged her to develop a principle to help her with the problem, and she responded by reflecting on the source of the conflict the tension between her desire for teachers to retain ownership of their 
teaching, and her desire to give direction to those who do not teach in the way that she thinks they should.

Rather than tell her what to do, David shared his own experience dealing with the same issue. She then was able to articulate a principle: "The important thing is to reflect on those times and try to figure out what made it work in the one case, but not in the other; or to analyze the most frustrating recalls and try to figure out what went wrong."

\section{Episode 2:}

Consultant: It would have been good to have done it there, and as I get better, hopefully it will be more programmed into my next response. If the tape is stopped and we've identified an issue, I will ask, "What are you going to do?" It's getting to be second nature for me to say that.

David: When you say, "It's getting to be second nature to me," what is the knowledge that you're referring to?

Consultant: The idea that just identifying...naming the issue...that they're dealing with is not sufficient. Now they know it exists...

David: But they need to develop a principle.

Consultant: They need to develop some ideas. They need to start that process of going, "Well, I could do this, or I could do that..."

David: Having some action to perform.

Consultant: ...because if they see that coming up on the tape, then they'll see alternative things they could have done, even as the session goes on.

David: How did you come to know that?

Consultant: Probably by listening to your rap.

David: Which rap is that?

Consultant: The idea, just what you did to me, that I have to formulate the thought, I have to put it into my own words, to think it through, to have somebody nudge me to do that, or I need to nudge them to carry it through. Say, "This is what I'm dealing with, these are ways I have of confronting this issue when it comes up."

David: Strategies.

Consultant: Right. That's the word.

David: But you've been doing this for seven years, so you've come to know this from other sources than by just observing me. 
Consultant: Yeah, we've touched on this before. I think some of the difference doing it just one-on-one with the TA is that you can put a lot more emphasis or focus on their thought process during the recall. If I'm helping to facilitate four or five students and the TA, there's a lot more free-for-all. When you have students there [in the recall session], part of the purpose is to get information from those students, so I feel like I can spend less time refining a single idea such as, "Let's look at the tape, let's see what comes out of these students." I think this is part of the learning process for me this fall. I've never done it this way, and I have to refine different skills than I used when I was trying to assess what's going on in a group, how to break some people out, how to start some people up, how to get the conversation - because there is a conversation - to be productive for the TA.

David: Part of the reason I asked you how you came to know that is because any knowledge that you have about consulting is in the context if you were going to teach [videotape recall] to someone. What is the knowledge you have, first of all, and how did you come to know it? [Those are] useful things for you to have your finger on in teaching someone else how to do [videotape recall].

Consultant: Part of it comes from having an articulated philosophy of what teaching is, what it means to be self-reflective. I say a few things out of a kind of therapy base: the idea that you sometimes have to go about changing your actions even though your gut's not going to come along with you right away. You don't feel comfortable calling on an individual by name to answer a question. Accept that it will feel better [later], but start by changing what you can change and then you find your feelings will come along and you'll be all right. But there's also this idea that if what you're trying doesn't work, try something new. The more things you have at your disposal-to pull out of the bag of tricks - the more effective teacher you're going to be. I certainly feel that way as a [consultant]. The more that I have done this and thought about it and paid attention to what works, discuss things with you and listen to you, you articulating the theory behind what we're doing, that makes it more possible for me to carry out that theory because I know the reason why.

David: You referred to a theory, which to my mind must be, in part, some sort of implicit theory, other than what you've heard me espouse. In your mind, what is this theory?

Consultant: It might, to sum it up, be self-reflective practice. The idea that if you can think about what you are doing as a teacher, and especially if 
you can talk about that, if you can look at yourself, and as you said somewhere last week, as soon as you're looking at it [on videotape], you're getting experience with what it's like to teach and watch yourself teach at the same time. If you can be aware of your thoughts and feelings in this process, the next time you're in front of the classroom, you've had some practice with this experience...the more self-aware a teacher can be of what their goals are...and believing that this process helps.

David: So believing is part of the process?

Consultant: Right...

The consultant seemed to feel comfortable with her role as consultant. She talks in generalities about the process, however, and several times David prompts her to focus on and articulate what it is that she does with clients: "What is the knowledge you're referring to?" "How did you come to know that?" "What is this theory?" By asking these questions, David is forcing her to examine her practice as a consultant as well as modeling the consultant's role in doing videotape recall.

\section{Episode 3:}

Consultant: I think...it's the whole idea I used to have that you can give something to somebody. Now I no longer think I can give anything to anybody. I can help them wrestle. I realize that it's their process to figure things out.

David: Legitimating that for them.

Consultant: Yeah. And do that by any of the techniques that I havehumor, pushing, badgering - whatever it takes to get the person engaged. A lot of what I go for, too, is affect. I want that person to have a relationship with whatever the subject matter is.

David: You mean have a kind of personal investment.

Consultant: Yeah, that there's got to be some kind of caring that goes on and that...I don't know, I haven't articulated this in a long time, it's not coming out very clearly, but $I$ believe that what they get out of a course is a sense, a feeling, toward the material, toward their own ability to master that material, much more so than the facts. I guess I'm a process person. I want the process of being engaged with some subject to be what counts.

David: The process of their learning is as valid as what they learn...

Consultant: Yeah.

David: ...and the quality of that process. 


\section{Consultant: Yeah.}

The consultant recognizes that her teaching is guided by an implicit theory, but she has not yet fully put that theory into words. David helps her to focus by prompting and questioning her until she can articulate her theory. He then paraphrases what she has said into one sentence: "The process of their learning is as valid as what they learn." The brevity and clarity of the statement allows her to reflect on her theory, to relate it to her practice, and to build upon her repertoire of self-knowledge.

\section{Some Personal Experimentation: Kate}

The other author of this article, Kate Brinko, discovered video recall after several years of videotaping classroom interactions of faculty and teaching assistants at a midwestern research-oriented university. During this time, she was concentrating on honing her techniques of providing feedback (see, for example, Blake \& Mouton, 1983; Ilgen, Fischer, \& Taylor, 1979), and providing feedback using several types of data, including observations (Hilsen, Brinko, Taylor-Way, \& Tiberius, 1987), student discussions (Clark \& Bekey, 1979), and videotape recordings (Fuller \& Manning, 1973; Perlberg, 1983). Her dissatisfaction with video feedback grew, however. Her video feedback sessions seemed to explore only superficial issues concerning presentational style; it became increasingly apparent to her that the technology was underutilized.

It was around this time that she received a draft copy of a book chapter that outlined the process of video recall (Taylor-Way, 1988). She experimented with the technique, but attaining proficiency was impossible without the aid of a colleague to coach and provide practice. Thus, she took the opportunity at the 1988 annual meeting of POD to obtain some face-to-face coaching and practicing (Brinko \& Taylor-Way, 1988) at an all-day pre-conference workshop.

Participants in that workshop also experienced many difficulties learning video recall, and confirmed some of Kate's impressions about it. First, video recall skills do not develop intuitively. For most participants in the workshop, criticizing superficial presentational techniques was easy; even the few participants who were not instructional consultants could offer their opinion about a teacher's presentation of material. Assisting a client to focus, conceptualize, and reframe a principle, however, required a great deal of concentration from participants, even the experienced consultants. Success with the technique usually came in fits and starts. 
Second, learning the techniques of video recall is quite difficult (if not impossible) without the support of a colleague consultant. In the workshop role-play exercises, participants often broke out of role to coach one another (e.g., "I think now maybe you should ask me what underlying concept I see in my teaching"), and spent a great deal of time discussing how to phrase questions that would elicit the kinds of responses that were desired from the "teacher." And third, learning to use video recall effectively requires time and effort. From the participants' performance in the workshop, it was apparent that video recall is not a technique that is casually learned in an afternoon. Although all participants thought that video recall was an important skill, many reported on their session evaluations that they needed more practice before they would feel comfortable using the process.

These three observations about the workshop participants' experience with video recall may discourage some from using video recall as a professional tool. If those with no consultation experience can provide superficial feedback using videotape recordings, however, how can we experienced consultants consider ourselves "professionals" if we can provide only the same superficial feedback? The above observations thus serve to strengthen our conviction that techniques such as video recall must be mastered if we are to thrive as a profession.

\section{Conclusion}

As members of a relatively new profession, we faculty developers have a special opportunity and responsibility to determine the direction and knowledge base of our profession. To withstand the test of time and budget reductions, it is imperative that we continually professionalize our activities in two ways: by producing increasingly sophisticated professional methodologies and by producing increasingly sophisticated professional knowledge. The technique of video recall is a professional methodology that can lead to professional knowledge.

We can also use video recall in instructional consultation sessions to help instructors construct their own professional knowledge. Rather than focusing only on superficial presentational issues, video recall techniques enable consultants to help instructors reflect upon their implicit theories of teaching.

Finally, we can use video recall in small collegial groups to foster reflective practice in our consulting. By using the same process that we use with faculty-focusing, conceptualizing, and reframing-on ourselves, we can greatly increase our professional knowledge base. 


\section{References}

Adams, R. S., \& Biddle, B. J. (1970). Realities of teaching: Explorations with videotape. New York: Holt.

Allen, D. W., \& Ryan, K. (1969). Microteaching. Reading, MA: Addison-Wesley.

Baker, H. P. (1970). Film and videotape feedback: A review of the literature. (Report Series No. 53). Research and Development Center for Teacher Education, University of Texas at Austin.

Bilberstine, R. D. (1971). The utilization of videotape equipment in teacher education. Contemporary Education, 42, 217-221.

Blake, R. R., \& Mouton, J. S. (1983). Consultation: A handbook for individual and organization development. Reading, MA: Addison-Wesley.

Bloom, A. (1987). The closing of the American mind. New York: Simon \& Schuster.

Bloom, B .S. (1953). Thought processes in lectures and discussions. Journal of General Education, 7(3), 160-169.

Bloom, J. M. (1969). Videotape and the vitalization of teaching. Joumal of Teacher Education, 20, 311-315.

Brantley, W. E. (1972). A study of the effects of videotaping on selected aspects of teacher classroom behavior. Unpublished doctoral dissertation, Lehigh University.

Brinko, K. T., \& Taylor-Way, D. (October, 1988). Videotape consultation. Workshop presented at the thirteenth annual meeting of the Professional and Organizational Development Network in Higher Education, Keystone, CO.

Burke, J. B., \& Kagan, N. (1976). Influencing human interaction in public schools. NIMH Grant \#MH 13526-01, Final Report.

Carrol, J. G. (1976). Effects of a teaching assistant training program on teaching behavior and student ratings of instruction. Unpublished doctoral dissertation, Cornell University.

Carus, F. E. (1968). The use of closed circuit television (videotape) and psycho-galvanic response to increase the rate of change in student teachers' classroom performance. Unpublished doctoral dissertation, University of California, Berkeley.

Clark, C.M., \& Yinger, R. J. (1977). Research on teacher thinking. Curriculum Inquiry, 7(4), 279-304.

Clark, D.J., \& Bekey, J. (1979). Use of small groups in instructional evaluation. POD Quarterly, 1(2), 87-95.

Dendy, R. F. (1971). A model for the training of undengraduate residence hall assistants as paraprofessional counselors using videotape techniques and interpersonal process recall (IPR). Unpublished doctoral dissertation, Michigan State University.

Eder, M. D. (1971). A study of the effectiveness of the videotape recorder with and without modeling in the in-service training of teachers. Unpublished doctoral dissertation, University of Maryland.

Fuller, F. F., and Manning, B. A. (1973). Self-confrontation reviewed: A conceptualization for video playback in teacher education. Review of Educational Research, 43, 469-528. 
Gallissich, J. (1982). The profession and practice of consultation. San Francisco: Jossey-Bass.

Hilsen, L., K.T. Brinko, Taylor-Way, D.G., \& Tiberius, R. (October, 1987). Individual consultation: A primer. Workshop presented at the twelfth annual meeting of the Professional and Organizational Development Network in Higher Education, Kerrville, TX.

Hirsch, E. D. (1987). Cultural literacy: What every American needs to know. Boston: Houghton Mifflin.

Ilgen, D.R., Fisher, C.D., \& Taylor, M.S. (1979). Consequences of individual feedback on behavior in organizations. Joumal of Applied Psychology, 64, 349-371.

Kagan, N. (1975). Interpersonal process recall: $A$ method of influencing human interaction. Michigan State Department of Counseling, Personal Services and Educational Psychology, East Lansing.

Kagan, N., Krathwohl, D. R., and Miller, R. (1963). Stimulated recall in therapy using videotape: A case study. Journal of Counseling Psychology, 10, 237-243.

Killbourne, B. (1988). Reflecting on vignettes of teaching. In P. P. Grimmett \& G. L. Erickson (Eds.), Reflection in teacher education (pp. 98-99). New York: Teachers College Press.

Lewis, K. (1988). Individual consultation: Its importance to faculty development programs. In K. Lewis (Ed.), Face to Face: $A$ sourcebook of individual consultation techniques for faculy/instructional developers (pp. 19-32). New Forums Press: Stillwater, OK.

MacKay, D.A., \& Marland, P. (1978). Thought processes of teachers, ERIC ED 151-328.

Mulac, A. J. (1969). An experimental study of the relative pedagogical effectiveness of three feedback conditions employing videotape and audiotape for student self-evaluation. Unpublished doctoral dissertation, University of Michigan.

Perlberg, A. (1983). When professors confront themselves: Toward a theoretical conceptualization of video self-confrontation in higher education. Higher Education, 12, 633-663.

Redmond, M.V., \& Clark, D. J. (1982). Student group instructional diagnosis: A practical approach to improving teaching. AAHE Bulletin, 34(6), 8-10.

Roberts, L. H. (1971). An investigation of self-identified student teaching problems in conferences with and without videotape recording feedback. Unpublished doctoral dissertation, Syracuse University.

Roush, R. E. (1969). A study of change in selected teacher education interns' behavior using videotape recordings. Unpublished doctoral dissertation, University of Houston.

Rowe, M. B. (1974). Wait-time and rewards as instructional variables. Journal of Research in Science Teaching, 11, 81-94.

Schon, D. (1983). The reflective practitioner: How professionals think in action. New York: Basic Books.

Schon, D. (1987). Educating the reflective practitioner. San Francisco: Jossey-Bass.

Shavelson, R.J., \& Stern, P. (1981). Research on teachers' pedagogical thoughts, judgments, decisions and behavior. Review of Educational Research, 51(4), 455-498. 
Schulman, L. (1986). Those who understand: Knowledge growth in teaching. Educational Researcher, Feb., 4-14.

Stoller, F.H. (1968). Focused feedback with videotape: Extending the group's functions. In G.M. Gazda (Ed.), Innovations in group psychotherapy (pp. 222-230). Springfield, Illinois: Charles C. Thomas.

Sykes, C.J. (1988). Profscam: Professors and the demise of higher education. Washington, DC: Regnery Gateway.

Taylor-Way, D. (1988). Consultation with video: Memory management through stimulated recall. In K. Lewis (Ed.), Face to face: $A$ sourcebook of individual consultation techniques for faculty/instructional developers. New Forums Press: Stillwater, OK.

Taylor-Way, D. (April, 1981). Adaptation of interpersonal process recall and a theory of educating for the improvement of college teaching. Paper presented at the annual meeting of the American Educational Research Association, Los Angeles.

Valine, W. J. (1974). Focused feedback with videotape as an aid in counseling underachieving college freshmen. Small Group Behavior, 2, 131-143.

Way, D. (1977). Video in the classroom and community. Unpublished master's thesis, Cornell University. 